\title{
A BIOLOGIA NOS MUSEUS DE CIÊNCIAS: A QUESTÃO DOS TEXTOS EM BIOEXPOSIÇÕES
}

\author{
M artha M arandino ${ }^{1}$
}

\begin{abstract}
Resumo: 0 artigo em questão discute a produção de textos em museus de ciências, a partir de dados obtidos em pesquisa de doutorado a qual buscou estudar o processo de construção do discurso expositivo em exposi ções ligadas ao campo da biologia. N este trabalho apresenta-se, inicialmente, 0 referencial teórico sobre o tema, onde se discute as características dos textos científicos, dos textos de divulgação e dos textos afixados em museus. Alguns exemplos dos textos estudados em cinco museus são apresentados, com base nos dados obtidos através da anál ise qual itativa das exposições. Elementos como formato, estrutura, edição e linguagem são analisados, buscando caracterizar a diferença entre os três tipos de textos e o processo de recontextualização pelo qual esses passam na elaboração do discurso expositivo. No que se refere às características dos textos existentes nos museus de ciências, destaca-se que estes nunca são exatamente iguais aos textos científicos ou aos textos de divulgação, apesar de possuírem alguns elementos em comum. Conclui-se que entender as especificidades da cultura museal e do público visitante é imprescindível para a produção dos textos nos museus e, neste sentido, pesquisas de público que avaliem as inovações tecnológicas e as características dos textos devem ser estimuladas, para que estes realmente auxiliem e promovam a leitura nesses locais.
\end{abstract}

Unitermos: museus de ciências; textos científicos, textos de divulgação e textos de museus.

Abstract: This paper discusses the process of elaborating texts to be used in science museums. It is based on data from a PhD thesis that studied the process of transformation of scientific discourse - particularly biological - into expositive discourse in the construction of exhibitions at science museums. Initially, the paper deals with theoretical references on the scientific text, the public communication text and the text presented in museum exhibitions. Examples of texts taken from five exhibitions were presented, based on data obtained through qualitative analysis. Aspects such as form, structure, editing and language were analyzed, aiming at showing the differences among the three kinds of text mentioned above. Also, these aspects were used to characterize the recontextualization process that occurs when the expositive di scourse is produced. In conclusion, one can say that the texts from science museums are different from scientific or public communication texts, despite their having common elements. It is necessary to understand the specificities of the museum culture and of the visiting public, in order to improve the production of science museum texts. Further research on evaluation of science museum texts is desirable if more and better reading of them is to be stimulated.

Keywords science musems, scientific texts, public communication texts and texts from museums.

\section{Introdução}

O s museus de ciências têm sido cada vez mais consagrados como locais fundamentais para o desenvolvimento da educação não formal em ciências. As atividades educativas desenvolvidas nesse espaço são de diferentes naturezas, e estratégias variadas têm sido propostas para realizá-las.

A educação em museus possui especificidades as quais vêm sendo ressaltadas por diferentes autores (Van-Präet e Poucet, 1992; Allard et all, 1996; Cazelli et all, 1999; $\mathrm{M}$ arandino, 2001) e elementos como espaço, tempo e objetos são considerados alguns dos fatores que irão constituir o diferencial da educação nesses espaços.

\footnotetext{
${ }^{1}$ Assistente D outora da Faculdade de Educação, U nivers dade de São Paulo. São Paulo, Brasil. A poio: CAPES (e-mail: marmaran@unisys.com.br)
} 
Além disso, a exposição pública é um dos elementos fundamentais da identidade do museu. 0 conhecimento deteorias, metodologias epráticas sobre exibições énecessário, poiséatra vés delas que o museu divulga a instituição, informa o público, muda atitudes e comportamentos, tendo assim a missão de promover espaço para a educação e reflexão. D ean (1994) procura aprofundar a temática das exposições afirmando que somente os museus possuem o papel social de "coletar, preservar, pesquisar e expor publicamente como função essencial de sua existência". Para Dean (1994:1), os museus se tornaram organizações multifacetadas, com múltiplos propósitos e múltiplas dimensões eapesar das diferentes opiniões sobre seu papel enquanto "espaço delazer" ou "templo de aprendizagem", eles se constituem como "elemento opcional para o diazadia da vida da maior parte da população". N o que se refere à aprendizagem em museus e a relação destes com a escola, D ean afirma que os museus oferecem "agradáveis possibilidades de assimilar informações" eque não se deve deixar de valorizar o "papel de entretenimento que as exposições proporcionam". É através das exposições que se dá à missão educacional dos museus, o que implica na importância de estudar os processos de desenvolvimento dessas unidades fundamentais.

Os elementos relativos ao espaço físico das exposições de museus de ciências formam, no seu conjunto, o sistema de signos que compõem o cenário das exposições. H ernández (1998:205), indica que para análise da comunicação nas exposições é importante o estudo dos "objetos, os textos, as fotografias, as maquetes, o espaço da exposição e a iluminação". 0 discurso expositivo é composto por uma série de elementos que dizem respeito não só aos objetos, mas a toda uma gama de signos e sinais que se expressam através dos objetos, dos textos, das vitrines, das imagens, dos modelos e réplicas, entre outros.

O s textos são elementos presentes nos museus e possuem variadas funções no espaço expositivo, desde sinalizações e indicações sobre circuito, até explicações sobre objetos e fenômenos. N esta perspectiva, este trabalho apresenta a análise dos textos presentes em museus estudados em pesquisa de doutorado, a qual procurou entender o processo de produção do discurso expositivo em museus de ciências. Para cumprir esta finalidade, os textos foram escolhidos como elementos fundamentais e analisou-se especialmente a produção dos mesmos, já que a investigação tinha como objetivo estudar os processos de transposição museográfica e de recontextualização na elaboração do discurso expositivo.

$\mathrm{N}$ a pesquisa foram estudadas exposições de cinco museus que abordavam temas ligados à biologia e a metodologia adotada se caracterizou por uma abordagem qualitativa, com entrevistas aos coordenadores das exposições, análise das próprias e análise documental. Para este trabal ho, foram utilizados os dados obtidos a partir da análise das exposições, a qual seguiu roteiro com base em quadro analítico que, dentre os diferentes itens, haviam aqueles relacionados à análise dos textos nos aspectos referentes à tamanho (texto e letra), formato (texto e letra), linguagem, articulação com imagens, diagramação, etc.

Para o estudo dos textos foram utilizados autores que têm discutido as características do texto/discurso científico, do texto/discurso de divulgação científica e do texto/discurso presentes em exposições de museus, e do processo de transformação de um texto/discurso no outro. Pretendeu-se desta forma perceber aproximações e distâncias entre esses três tipos de textos, com a finalidade de compreender o papel e as características dos textos e os processos de transformação pelos quais passam na elaboração do discurso expositivo.

\section{0 papel dos textos nos museus de ciências}

Sobre o papel dos textos na comunicação museográfica, Jacobi (1998:277), com base na perspectiva da exposição como uma mídia que combina diferentes registros semióticos (objetos, cenografia, vitrines, dioramas, espécimes, etc.), indica que os textos nos museus não são apenas um 
dos elementos plásticos para compor a cenografia. Este autor discute a trajetória da utilização dos textos em museus, diferenciando o seu uso nos museus de arte e de ciências.

Segundo Jacobi (1998:278), nos museus de arte os textos estão reduzidos em detrimento da exibição das "obras". 0 pouco uso do texto nesses locais, para ele, tem como pressuposto, muitas vezes, uma idéia "mítica ou mesmo inapropriada" de que as pessoas teriam um dom estético inato. 0 que se processou nos museus de arte, então, foi o desaparecimento dos textos, sendo reduzidos a menções mínimas em cartazes ou em documentos complementares. N o entanto, para este autor, esses tipos de documentos são muito lidos pelos visitantes, ao contrário das esculturas e quadros, pois tratam de um universo familiar ao público.

Por outro lado, de acordo com Jacobi, nas exposições científicas os textos são usados constantemente, como etiquetas para identificação de espécimes e de amostras para auxiliar o visitante a compreender os conceitos ou a interpretar maquetes e reconstituições, ou ainda como notas para guiar a utilização de um dispositivo interativo.

Atualmente, nas exposições científicas contemporâneas os textos aparecem de diferentes formas no espaço expositivo. As novas tecnologias - hipertextos, vídeos, internet, etc., são muitas vezes utilizadas como suportes diferenciados em relação às tradicionais etiquetas e painéis para expor textos nesses locais. No que se refere aos textos afixados nos museus, Jacobi (Ibid., p.276) levanta uma série de questionamentos quanto ao fato das novas tecnologias de comunicação não estarem levando ao desaparecimento desses recursos nos espaços expositivos. Para ele, a presença da escrita nos museus provoca interrogações relacionadas a sua utilidade, a quem se destina, a que momento da visita, ao como são produzidos, se são lidos, quem os consulta preferencialmente, que impactos têm sobre as diferentes categorias de leitor e se é possível medir o efeito cognitivo e afetivo da escrita e como isso se dá.

O s textos afixados nos museus, de acordo com Jacobi (1998:284), são um objeto pouco estudado. Para ele é necessária a realização de pesqui sas empíricas de avaliação dos textos, através de introdução de pequenas modificações controladas. Além disso, indica que, se por um lado as pesquisas sobre os textos escritos são raras nos museus, as aval iações real izadas se apóiam em grande parte nesses elementos, o que evidencia o papel secundário dado à complexidade dos textos dos museus. De acordo com Jacobi (I bid., p.284), os visitantes, mesmo os que acompanham todo o percurso da exposição, não lêem tudo que está afixado, pois isso seria impossível e desprovido de sentido. Eles, na verdade, fazem escolhas, sendo então fundamental os estudos de comportamento e modos de leitura nesses locais. Pesquisas sobre a escrita na educação não formal e nos museus, na opinião de Jacobi, permitem levantar questões sobre a utilidade da escrita científica. Investigar o "porquê" e "em que" momentos os textos são lidos nas exposições têm mostrado o seu incontestável papel. Entretanto, há muito a ser pesquisado quanto ao efeito cognitivo e afetivo da escrita nesses locais.

\section{ciências}

\section{0 texto científico, o texto de divulgação científica e o texto de museus de}

Uma série de investigações tem procurado analisar as características, especificidades e funções dos textos no processo de socialização do conhecimento científico. Para caracterizar o texto científico, G ouvêa (2000), por exemplo, indica que os textos em geral podem ser classificados pela sua estrutura - formas de construção - ou pelas suas diferentes funções comunicativas e sociais. Logo, não seria somente a estrutura que diferenciaria o texto científico dos demais, mas também sua sintaxe e o conjunto léxico utilizado. Segundo esta autora o texto científico seria uma variante do texto argumentativo, já que sua estrutura é "composta por colocação de problema, justificativa, solução e conclusão, sendo estas partes necessárias a uma argumentação" (G ouvêa, 2000:81). 
No que se refere ao texto de divulgação, G ouvêa (2000) toma por base o texto jornalístico, afirmando que este obedece rigorosamente aos cânones comunicacionais, privilegiando assim o receptor. A linguagem desses textos tende a se aproximar da linguagem cotidiana, "apoiando-se em metáforas e analogias para tornar as exposições claras" (Ibid., p.85). Para esta autora, na transformação de textos científicos em textos de divulgação ou de ensino duas questões estão colocadas: a primeira refere-se à estrutura do texto (que linguagem utilizar) e a segunda às entidades contidas nesses textos. Para transformar o texto científico em texto de divulgação seria preciso romper com a sua estrutura conceitual, significando assim "destruir o conceito": "Por isso, nos textos de divulgação científica, convivem duas linguagens e, portanto, as duas formações discursivas - da ciência e do jornalismo" (Idem., p.86).

0 utros autores discutem as características do texto científico a partir de suas estruturas sintáticas e do seu conjunto léxico, isto é, a linguagem científica. M ortimer e M achado (1997), por exemplo, indicam algumas características da linguagem científica, em contraposição a linguagem do senso comum. Enquanto a linguagem cotidiana é linear, apresenta uma ordem estabelecida e mantida e possui um narrador sempre presente, a científica seria estrutural, estando 0 agente normalmente ausente, tornando-a assim descentralizada, sem a perspectiva de um narrador. $\mathrm{Na}$ linguagem científica, os grupos nominais substituem as ações representadas pel os verbos, retirando assim o agente. Além disso, o processo de nominalização aumenta a densidade léxica da linguagem científica, na qual todos os termos usados carregam significados interligados numa estrutura conceitual: "A linguagem científica substitui os processos, expressos normalmente por verbos, por grupos nominais, assim, ocorre a substituição de uma classe ou estrutura gramatical por outra" (M ortimer e M achado, 1997:211).

Leibruder (1999) afirma que discurso científico caracteriza-se pelo emprego de uma linguagem objetiva, concisa e formal, com o uso de um padrão lexical - nominalizações, vocabulário técnico, emprego de verbo na 3a pessoa acrescido da partícula "se" (indeterminação do sujeito) ou $1^{\text {a }}$ pessoa do plural (sujeito universal). Estes elementos caracterizam o apagamento do sujeito no discurso científico, o afastamento do "eu", camuflando a subjetividade, conferindo ao texto científico um caráter de porta-voz da verdade, intermediário entre a natureza e o homem, assumindo uma perspectiva de neutralidade e de inquestionabilidade. Assim os índices de impessoalidade - apagamento do sujeito - são mecanismos argumentativos com finalidade de provar a veracidade e legitimidade do discurso científico, sendo este um fazer persuasivo (Leibruder, 1999:230).

Q uanto às características do discurso de divulgação científica, para Leibruder (Ibid., p.233), este é formado pela intersecção de dois gêneros de discurso: 0 científico e o jornalístico. Assim seriam dois tipos de linguagens expressas neste texto: a objetividade e suposta neutralidade científica e a tendência a um registro mais coloquial, mostrando uma certa subjetividade. N a produção do texto de divulgação, o divulgador opera uma "tradução intralingual" (M ortureux, 1982, apud Leibruder, Idem., p.234), incorporando ao fio do discurso elementos lingüísticos e extral ingüísticos referentes à própria experiência do leitor. D esta forma, o discurso de divulgação possui al gumas características específicas, como por exemplo, um caráter metalinguístico, ou seja, a capacidade de se auto-explicar, utilizando assim elementos didatizantes como definição, nomeação, exemplificação, comparação, metáforas, parafrasagem, além da escolha lexical e do uso de elementos visuais.

O utra característica do discurso de divul gação, segundo Leibruder, é o fato de se tratar de uma atividade de formulação e reformulação discursiva, não sendo mera tradução do discurso científico. É, na verdade, um "fazer discursivo". 0 texto de divulgação científica, ao ser produzido, incorpora alguns dos elementos dos textos científicos, quando quer se aproximar 
do científico. No entanto, o texto de divulgação não deve ser tão formal, já que deve assumir um formato atraente: "Para tanto, o jornalista utilizará recursos lingüísticos (metalinguagem, narratividade, título, resumo) e extralingüísitco (recursos visuais - fotos, tabelas, gráficos, esquemas) capazes de suscitar o interesse do leitor" (Leibruder, 1999:237).

Assim, pode-se concluir que na produção do discurso de divulgação, há mudança de "cenário discursivo", das "posições ocupadas pelos interlocutores", já que, mas do que um trabalho de reformulação discursiva, há a formação de um "novo discurso" (Zamboni, 1997, apud Leibruder, 1999), com características e finalidades próprias. As reformulações são etapas e não a finalidade desse novo discurso, por isso utilizam-se recursos didatizantes. Tais recursos têm por base a idéia de que o público possui variado grau de conhecimento, havendo a necessidade de seleção dos mesmos pelo divulgador e de diferentes estratégias discursivas. D esta forma, as escolhas são feitas a partir da imagem do destinatário e do valor social atribuído aos recursos estilísticos disponíveis da língua - o que considera adequado ao seu público-alvo.

Jacobi (1998) vai discutir a questão dos textos afixados em museus e, para tal, analisa as características dos textos científicos e de vulgarização e, especificamente dos textos nos museus. Segundo Jacobi (1998:268) existem três pólos de comunicação científica: o do discurso primário, ou seja, de pesquisadores para pesquisadores; o discurso de vocação didática, referente aos textos dos manuais de ensino da ciência; e o de educação científica não formal, ou seja, os de vulgarização. Esses três pólos, para este autor, variam de autoria, de público-alvo, de suporte e de amplitude de difusão.

Sobre os textos científicos, este autor indica que estes possuem características bastante conhecidas, tratando-se de um texto "esotérico", o qual segue um plano padrão: introdução, material e métodos, resultados, discussão e conclusão. Utiliza uma terminologia específica e nele o "eu" (sujeito) é omitido, havendo uso freqüente da voz passiva (I bid., p.269).

0 texto de vulgarização, em contrapartida, para Jacobi (Idem., p.271) possui uma retórica própria e as modificações que sofre são designadas por uma série de verbos: "escolher", "trans formar", "modificar", "reestruturar", "reformular". 0 autor analisa o que acontece com o texto em cada um desses casos, procurando mostrar que tanto o discurso científico como o discurso de vulgarização, realizam seleções e reformulações, entretanto as fazem com objetivos diferentes.

Para este autor, os termos científicos são necessários, mas devem ser reformulados no texto de vulgarização. Para ele, o discurso científico vulgarizado "corresponde a uma empreitada que se situa no coração de uma contradição", já que o sentido dos conceitos especializados cons truídos pela ciência implica a necessidade de se usar uma linguagem especializada, mas esta é incompreensível ao público. Assim o escritor tem que recorrer a mecanismos de reformulação.

No que se refere à legibilidade dos textos afixados nos museus, Jacobi (I bid., p.279) indica três características que influenciam sua natureza: o formato, a estrutura e a edição do texto. 0 formato diz respeito ao tamanho, número de informações e a presença daquilo que é considerado essencial, já que a dificuldade para o escritor é "dizer em poucas palavras aquilo que é importante a propósito do objeto". A escolha do tipo de informação também se relaciona ao que se quer transmitir e ao interesse do público, existindo assim uma tensão na produção dos textos relacionada com os objetos e com as características do público. Ainda segundo 0 autor, existe uma literatura considerável do tipo prescritivo sobre os textos afixados nos museus, ou seja, publicações que fornecem critérios e parâmetros para elaboração dos mesmos, a qual, entretanto, nem sempre realiza uma reflexão sobre o tema.

Levando em conta esses aspectos, Jacobi se pergunta sobre o texto de museu questionando se o mesmo não seria anônimo e inexpressivo. As descrições impessoais, a retirada do "eu" (no caso do autor) e do "tu" e você" (no caso do destinatário do texto), contribuem 
para fazer com que "as coisas falem sozinhas". Para este autor, através do uso dos "pronomes pessoais, das formas de conjugação, das modelizações adverbiais, das estruturas interrogativas" se pode determinar as características e a qualidade enunciativa de um texto de museu. Assim, as formas de ausentar o escritor do texto ocorrem através do desaparecimento do "eu", do uso das formas passivas e empregando sistematicamente a estrutura impessoal ou vaga da $3^{\text {a }}$ pessoa. A objetividade conseqüente da neutralidade acaba por conferir um frio distanciamento, comum nos textos dos museus clássicos.

No caso dos museus de ciências, Jacobi reforça que a linguagem especializada é necessariamente presente e neles ocorre o uso de técnicas como sinônimo, reformulação de termos específicos e uso de negrito ou itálico para ressaltar termos ou expressões, mecanismos estes comuns também aos textos de divulgação. No entanto, no caso dos textos de museus, 0 recurso de sinônimos, de parafrasagem ou de substituição, segundo Jacobi (Idem., p.282), não são tão freqüentes quanto nos textos de vulgarização e existem duas hipóteses para isso. N os textos afixados em museus ocorre, em muitos casos, a escolha por ajustar a linguagem, objetivando atender o visitante especializado e, nestes casos, as reformulações e o tratamento metalingüístico não são necessários e podem, inclusive, ser considerados "vexatórios". Uma outra explicação para esta constatação, segundo o autor, diz respeito à estrutura, pois como os textos dos museus devem ser reduzidos e os resumos possuem grande poder nesses espaços, o uso de mecanismos lingüísticos acaba deixando-o mais denso.

Para 0 autor em destaque, os textos nos museus possuem particularidades que os diferem dos textos científicos e dos textos de vulgarização. A análise de seu formato, estrutura e edição, além de sua função, fornecem parâmetros para a caracterização desse tipo de texto. Processos de reformulações ocorrem e são necessários na sua produção, resultantes da tensão entre a complexidade e a quantidade de informação e a clareza e correção ao expô-la.

O utros autores também discutem as características dos textos dos museus numa perspectiva mais prescritiva e alguns desses trabalhos têm se preocupado em propor e avaliar técnicas de elaboração de textos em museus. Ekrav (1994), por exemplo, uma escritora de livros ingleses para adultos do tipo "easy-to-read", discute o uso desse estilo de literatura aplicada aos textos de museus. N esse trabalho esta autora propõe que muitas das dificuldades de leitura em museus se relacionam aos aspectos físicos e que a adoção desse estilo "easy-to-read" não significa que o conteúdo deva ser simplificado: "as sentenças são curtas, a ordem normal das palavras é preferível e as linhas devem ter aproximadamente quarenta e cinco caracteres. 0 final da linha do texto coincide com o final natural da frase. 0 rações subordinadas e advérbios desnecessários são evitados" (Ekrav, 1994:201).

Gilmore e Sabine (1994) procuram avaliar o "método Ekrav" na produção de textos em exposições e concluem que é fundamental o conhecimento de que ler textos em exposições não é a mesma coisa que ler textos em um livro: "O leitor está em pé, a uma certa distância, em público, e freqüentemente não familiarizado com o material a ser lido. Escrever para tais condições de leitura demanda habilidades especiais" (Gilmore e Sabine, 1994:205).

Em outra perspectiva, Coxall (1994) propõe que os textos nos museus são agentes ativos que moldam opiniões e identidades. Ao seu ver a linguagem é socialmente determinada e articula ideologias nas suas entrelinhas e, por esta razão, os escritores devem estar atentos, procurando identificar que concepções permeiam os textos que produzem. Através de exemplos de etiquetas em museus, C oxall (1994:215) demonstra como as variáveis lingüísticas como a voz passiva, as estratégias de nomeação e os significados construídos podem conter posições "racistas, sexistas ou enviesadas de alguma forma", as quais os escritores podem não querer apoiar. 
D esta forma, pode-se concluir que existe uma série de diferenças entre os textos científicos, os textos de divulgação ou vulgarização e os textos dos museus de ciências. M uitas das questões e desafios na elaboração desses três tipos de textos são, no entanto, compartilhadas. Além disso, existem algumas aproximações nas suas estruturas e nas suas formas.

\section{Analisando textos em bioexposições}

Para análise dos textos existentes nos museus serão apresentados, neste item do trabalho, alguns exemplos das exposições estudadas na pesquisa de doutorado anteriormente referida. D urante o aprofundamento teórico e a coleta de dados da pesquisa, os textos foram escolhidos como elementos fundamentais para compreensão do processo de elaboração do discurso expositivo. Para estudá-los, foram selecionados trechos representativos das exposições os quais foram copiados e registrados através de fotografias. Procedeu-se a análise dos mesmos a partir de categorias construídas com base no referencial teórico mencionado e objetivando 0 estudo do processo de recontextualização (Bernstein, 1996) pelo qual os textos passam na construção do discurso expositivo.

Assim um primeiro aspecto importante a ser destacado refere-se à forte presença de textos com características de textos científicos nas exposições dos cinco museus observados. Em um dos museus (M 1), por exemplo, onde a organização da exposição se dá em torno da sistemática e os objetos estão distribuídos pelos grupos taxonômicos ao longo do espaço expositivo, existe uma pequena quantidade de textos expostos. Q uando aparecem, estes são em geral referentes às etiquetas de identificação taxonômica ou explicações básicas sobre comportamento dos animais. São em geral sucintos, formados por períodos curtos, sem o uso de verbos de ligação. A pós a imagem, encontra-se o texto existente na etiqueta ao lado do objeto.

\section{Fig. 1 - Imagem da Arraia "Treme-treme" na exposição do M 1}

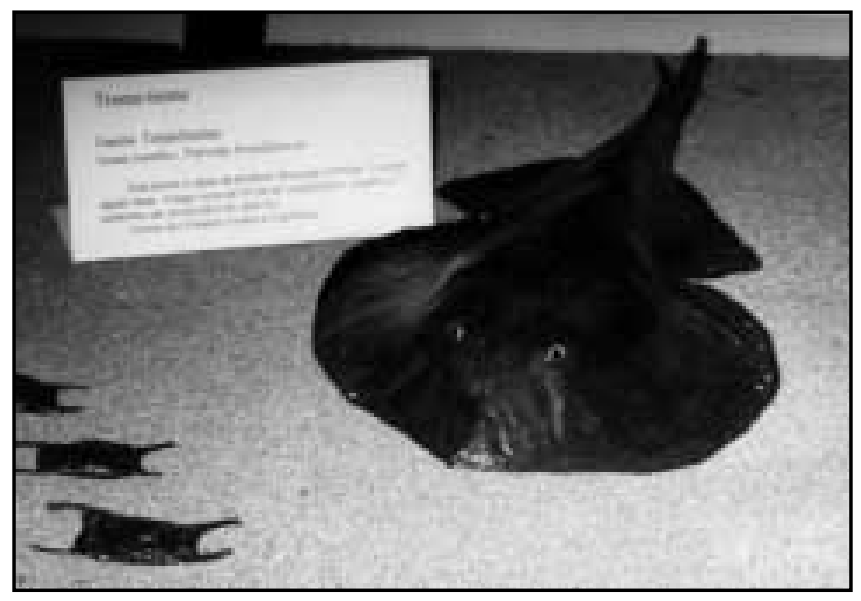

Treme-treme

Família: Torpedinidae

Nome científico: $N$ arcine brasiliensis

Esta arraia é capaz de produzir descargas elétricas. Vive em águas rasas. Atinge cerca de $50 \mathrm{~cm}$ de comprimento. Q uatro a 15 embriões são produzidos de cada vez. 0 corre dos Estados Unidos à Argentina 
No que se refere ao tipo de informação fornecida nos textos, outro dos museus estudados (M 2) também apresenta, em grande parte, a identificação taxonômica e indicações sobre a distribuição geográfica e características biológicas e comportamentais. Essas informações estão nas etiquetas referentes aos animais conservados e esqueletos.

A pesar da grande presença de textos com características de textos científicos em todas as exposições estudadas, encontram-se também outros tipos de textos nesses locais. Em al gums momentos nesses dois museus citados - M $\mathbf{1}$ e M $\mathbf{2}$ - foi possível encontrar etiquetas com informações mais detalhadas sobre al guns organismos ou mesmo sobre técnicas de conservação. U m exemplo é apresentado a seguir, presente em M 1:

PEIXES DIAFAN IZADOS

A diafanização (de diáfano = transparente) é um processo utilizado pelos pesquisadores para estudar o esqueleto de animais pequenos.

0 processo consiste em submeter 0 animal a uma substância que desmancha a musculatura mas mantém intactos o esqueleto e 0 tecido conjuntivo que une as diversas partes dele. Em seguida, um corante é utilizado para tingir os ossos de vermelho e outro é utilizado para tingir as cartilagens de azul.

No texto acima identificam-se al gumas estratégias comuns aos textos de divulgação, como a definição da técnica de conservação entre parênteses e o uso da parafrasagem, ao introduzir a palavra "desmancha", palavra esta de uso comum, para explicar o que ocorre durante o processo de diafanização.

O utros exemplos de elementos didatizantes podem ser identificados nos textos das exposições estudadas. Em algumas situações a linguagem é diferenciada na medida em que provoca o público para realizar atividades participativas em relação aos objetos expostos durante a visita. Em geral, estas exposições estão voltadas para o público que a visita, utilizando por vezes uma linguagem mais próxima da experiência cotidiana e estimulando 0 envolvimento através de manipulação e da observação dos objetos. É o que pode ser visto em M 2, por exemplo:

Fig. 2 - "O lhe, observe e compare" - Lema da exposição de M 2: estímulo a participação ativa do visitante.

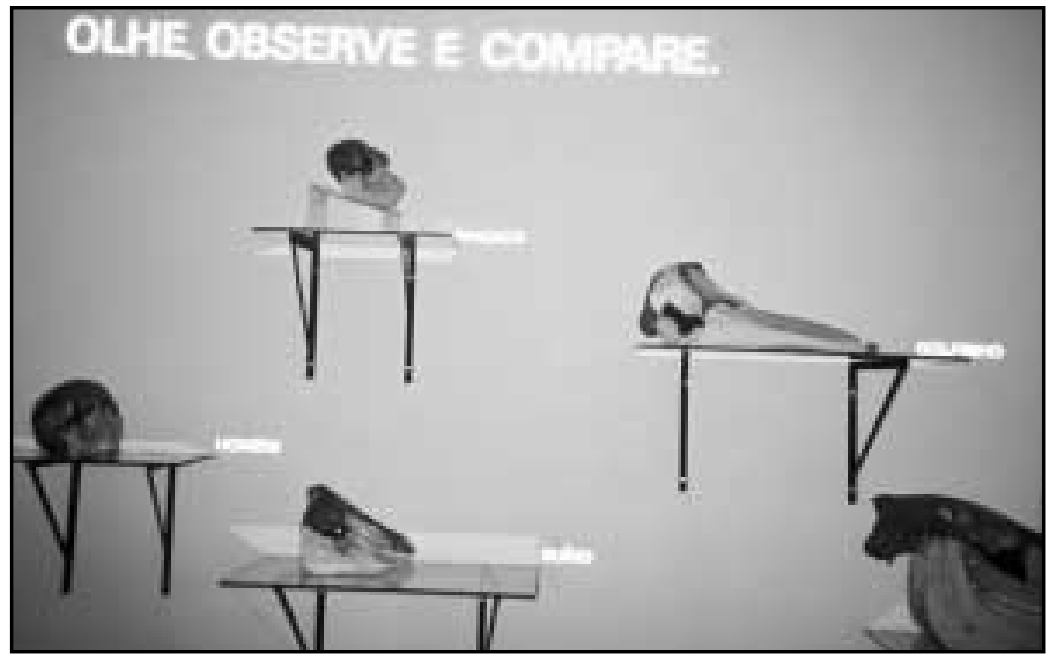


Do ponto de vista da organização, as duas exposições até aqui indicadas assumem uma abordagem sistemática ou di sciplinar, ao agrupar os objetos de acordo com os grupos taxonômicos ou através da estrutura da disciplina ou área de conhecimento. No entanto, identificam-se momentos onde as exposições rompem com essas abordagens, selecionado um tema e organizando a exposição ao redor dele. É o caso da exposição sobre "O Coração" em M2. $\mathrm{N}$ ela, os textos não são longos e oferecem informações específicas sobre este tema e sobre as técnicas empregadas para conservação deste órgão. Esses conteúdos são apresentados, nesta parte da exposição, de forma bastante diferente das demais: há dois painéis com imagens e esquemas do corte transversal do coração, identificando suas partes e com textos aprofundando o tema. 0 esquema do coração tem bastante semel hança com aqueles tradicionalmente utilizados nos livros didáticos escolares.

Em outro do museu estudado - M 3 - os textos possuem em grande parte semelhança com os textos científicos. Esse fato pode ser percebido ao abordar o tema sobre as " $M$ arés" e um dos textos desta parte da exposição foi reproduzido a seguir:

(1) "As M arés

São conseqüências de forças atuantes no planeta, provocando um movimento cíclico de avanço e recuo da água do mar. Este movimento ocorre devido às forças de atração solar e principalmente lunar, além da força centrífuga resultante do movimento orbital da Terra. Portanto o que controla as marés é um sistema formado pelo Sol, Terra e Lua."

Por outro lado, em M $\mathbf{3}$ também existem momentos quando os textos assumem características de textos de divulgação, através do uso de explicaçôes e de recursos estilísticos e visuais para auxiliar a compreensão do tema pelo visitante. Esta exposição se estrutura segundo a lógica disciplinar da área de conhecimento de referência deste museu.

É interessante também notar que mesmo utilizando aparatos multimídia nas exposições, essas podem manter em seus textos a estrutura do texto científico. Em outro museu estudado - M 4 - foi possível perceber esse fato quando foi abordado o tema das "Aves U rbanas". $\mathrm{N}$ esta exposição, as informações que estão no hipertexto associado a um aparato multimídia são basicamente sobre a sistemática, biologia e comportamento desses animais. Segue um exemplo:

Beija-flor-rabo-de-tesoura. Eupetomena macroura (G melin, 1788). D estaca-se de outras espécies pelo maior porte e pela cauda comprida e bifurcada, o que the vale o nome popular. Como é comum entre os beija-flores, é uma espécie agressiva que disputa com outras o seu território e fontes de alimento.

Alimentação: néctar de flores que coletam com a língua longa e tubular. São atraídos especialmente por flores vermelhas e laranjas, mas visitam também flores brancas e amarelas. Além do néctar, capturam pequenos artrópodos.

$\mathrm{N}$ idificação: o ninho, em forma de tigela, é assentado em uma forquilha de arbustos ou árvores, a cerca de 2 a $3 \mathrm{~m}$ do solo. 0 material utilizado na construção é composto por fibras vegetais incluindo painas, musgos e líquens, aderidos externamente com teias de aranhas. Entre os beija-flores, é tarefa da fêmea a construção do ninho e a incubação, durante 16 ou 17 dias, dos 2 ovos brancos; também cabe a ela a alimentação dos filhotes, que permanecem no ninho de 20 a 30 dias.

$\mathrm{H}$ abitat: capoeiras, cerrados, borda de matas e jardins

Tamanho: $17 \mathrm{~cm}$. 
0 texto existente nesta exposição é semelhante ao texto científico, já que não são utilizados elementos didatizantes nem verbos de ligação, estando a narrativa apresentada de forma impessoal. Entretanto, ressalta-se que a mediação do programa multimídia com o visitante estimula um envolvimento emocional e lúdico com a exposição.

Ainda em M 4, outra exposição encontrada neste local trata a questão do texto de forma particular, em função da sua história e origem, já que nela a linguagem é apresentada diferentemente se comparada com os demais espaços expositivos deste museu. 0 tema desta exposição é sobre os animais peçonhentos, principalmente as serpentes, e tem por objetivo informar e divulgar mensagens de preservação desses animais na perspectiva da educação ambiental, direcionada para o público infanto-juvenil. N uma das vitrines/terrários existentes, o qual possui uma serpente viva em seu interior, existe a seguinte etiqueta:

Sou da família das grandes serpentes, os Boídeos. M as não temos nada a ver com bois! Como todas as cobras, temos veneno, mas não usamos para caçar, porque não temos dentes especiais para injetá-lo. Esse veneno fica misturado na saliva.

(Esquemas)

N ós, as cobras, que também somos seres vivos, como vocês e outros animais, somos importantes na natureza. Já pensou nisso?

N ossa vida também depende de nossos pulmões, coração, rins, estômago, cérebro, como a sua.

Como não temos braços nem pernas, usamos a força muscular do nosso corpo para caçar os animais que são nosso alimento. G ostamos de caçar a noitee, para tanto, temos a pupila em fenda vertical (olho de gato).

N os alimentamos, crescemos, e para isso usamos nossos próprios meios: um corpo esguio, força muscular, ou veneno, afinal patas não temos.

Respeite nossos espaços. N ós dependemos das matas que os seres humanos insistem em derrubar e queimar! Pense nisto!

Ainda nesta exposição existe uma sala dedicada a exploração manual de material biológico conservado. Esses objetos se encontram em um móvel chamado "gaveteiro" ena sala existem imagens de uma serpente pintada na parede se comunicando com o público.

\section{Fig. 3 - Imagem de visitantes observando o conteúdo do G aveteiro em M 4: Atrás a cobra personagem dialoga com o público}

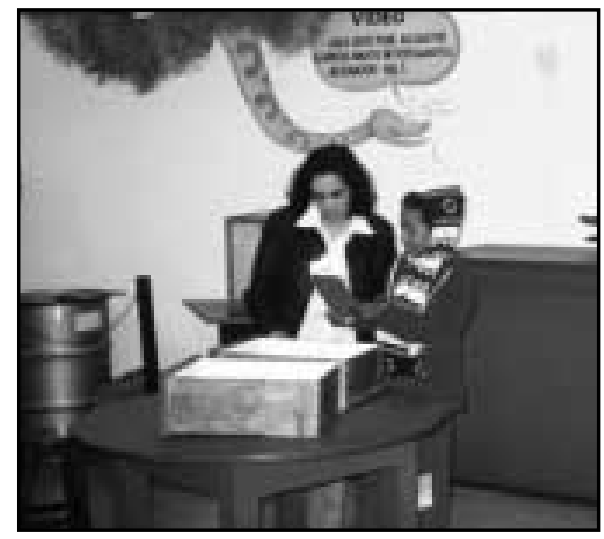


N os textos desta exposição de $\mathbf{M} \mathbf{4}$, a linguagem coloquial utilizada tem a função de aproximar a linguagem científica da cotidiana. Além disso, nestes textos são utilizados vários elementos didatizantes, como definição, metáfora e parafrasagem, entre outros. 0 mais marcante, porém, é o uso da primeira pessoa, dando a cobra um papel de agente na construção do texto. N esse caso, mais do que autoria existe um trabalho de personificação do animal, que não só pode falar, mas é capaz de possuir e sentir a mesmas coisas que os seres humanos. Essa escolha lexical tem a função de trazer 0 animal para o universo do visitante, especialmente do público infantil e, ao mesmo tempo, divulgar uma mensagem de preservação dos seres vivos.

Um outro exemplo de textos em exposição foi identificado no último museu estudado na pesquisa - M 5. N esta exposição é grande a presença de textos, os quais apresentam características especiais no que se refere à sua apresentação nos painéis e nos hipertextos em computadores. 0 público foi elemento fundamental na concepção desta exposição, o que pode ser evidenciado, por exemplo, através da diagramação dos painéis, que sempre articulam texto e imagem, com a função explicar e exemplificar o tema abordado. Além disso, percebese 0 uso de estratégias que demonstram o caráter metalingüístico do texto: presença de exemplificações, de metáforas, de defini ções e de nomeação, além do uso de um tipo de linguagem que provoca o visitante através de questionamentos sobre o conteúdo exposto.

\section{Painel}

Como surgiram tantos seres vivos?

Será que eles se transformam com o tempo?

Pensava-se antigamente que cada espécie animal criado por D eus era imutável. Todos os animais que sáram da Arca de N oé, após o dilúvio, seriam iguais aos de agora.

Se assim fosse, como explicar os fósseis de uma variedade de estranhos animais? Como explicar, também, que o homem transforma as espécies animais e vegetais através da domesticação.

\section{$2^{\circ}$ Painel}

Entre os séculos XVII e XIX, quando os estudiosos começaram a questionar cada vez mais os dogmas religiosos, as idéias sobre transformação dos seres vivos através dos tempos começaram a se impor.

Para Buffon, o clima e a vegetação eram os principais fatores responsáveis pela transformação das espécies.

O s ursos polares adquiriram uma grossa pelugem para se proteger do frio. [imagem de um urso]

[imagem de Buffon] 0 naturalista francês Buffon (1707-88) trabal hou como intendentedo do Jardin de Plantes de Paris. D escreveu diversas espécies de animais e vegetais, apresentados em um dos mais vastos trabalhos de história natural de sua época.

Para Lamarck, os indivíduos transmitiam aos seus descendentes suas transformações adaptativas, os caracteres adquiridos.

[imagem de Lamarck] 0 francês Lamarck (1744-1829) expôs sua teoria sobre a evolução, em 1809, na obra Zoological Philosophy.

Para suportar a falta de alimentos no deserto, o dromedário é dotado de uma reserva de gordura em sua corcova, usada como combustível sobressalente.[foto de um dromedário] [desenho de girafas] 
Segundo a teoria de Lamarck, a girafa teria adquirido o hábito de esticar o pescoço devido à necessidade de alcançar al imentos nas copas das árvores. Com o uso freqüente, 0 pescoço se desenvolveu e esta característica acabou sendo incorporada pelas gerações descendentes.

D urante muito tempo, acreditou-se que a Terra possuía a mesma estrutura geológica desde sua criação. 0 evolucionismo só teve um sólido ponto de apoio com o reconhecimento de que ela se transformava com o tempo.

Em 1832, Charles Lyell, em seu Princípios de Geologia, mostrou a sucessão histórica das camadas geológicas da Terra, tomando por base as características minerais e os fósseis nelas existentes. Foi um golpe nas teorias que propunham a imutabilidade da estrutura física da Terra através do tempo.

Ao tornar dinâmica a história do globo, Lyell preparou o cenário para uma possível mudança biológica contínua.

[imagem de Lyell] 0 geógrafo Charles Lyell (1794-1975) mostrou que a estrutura da Terra se transforma com o tempo.

[escrito no painel por trás das imagens existem as palavras BUFFO N e LAM ARCK ]

Em relação à organização, tanto as exposições em $\mathbf{M} \mathbf{4}$ quanto em $\mathbf{M} \mathbf{5}$ estão estruturadas ao redor de eixos temáticos, não seguindo assim a lógica disciplinar ou da sistemática, como nos demais museus.

O s elementos evidenciados anteriormente levam a afirmação de que tantos textos com características de textos científicos quanto com características de textos de divulgação estão presentes nos museus de ciências estudados. $\mathrm{N}$ o entanto, quanto mais assumida a concepção de museu voltada para o público, onde são considerados conhecimentos dos campos da comunicação e da educação na elaboração do discurso expositivo, mas os textos dos museus assumem características dos textos de divulgação, se afastando assim das características do texto científico.

Assim, em $\mathbf{M} \mathbf{1}$ e $\mathbf{M} \mathbf{2}$ e grande parte de $\mathbf{M} \mathbf{3}$ são mais comuns os textos com características de textos científicos, sendo também intensa a existência de objetos "científicos" e "naturais" ${ }^{\prime \prime}$ nesses locais. De um modo geral, os textos existentes nessas exposições concentram suas informações sobre a sistemática e taxonomia dos animais expostos, haven do somente casos pontuais onde outros tipos de características sobre esses seres são fornecidos. A linguagem utilizada nesse caso é nominalizada, não havendo uso de verbos de ligação e não há uma agente pre sente no texto. D esta forma, grande parte dos textos existente nestes museus apresenta características muito próximas a dos textos científicos. A própria organização da exposição, onde os animais são apresentados de acordo com os grupos taxonômicos ou dentro da lógica disciplinar, imprime um caráter e científico a narrativa proposta pelo conjunto da exposição.

$\mathrm{Na}$ medida em que as exposições se apresentam em torno de eixos temáticos relacionados a conteúdos biológicos, rompendo com apresentações sistemáticas ou disciplinares, também aumenta a quantidade de textos com características de textos de divulgação. É o caso do "coração", em M 2. Em M 4 os textos al gumas vezes possuem características de textos científicos, mesmo estando associados a mídias ou a objetos que promovem uma maior "interatividade" entre o público e a informação. $\mathrm{N}$ as exposições de $\mathbf{M} \mathbf{4}$ e em $\mathbf{M}$ 5, há predominância de textos com características de texto de divulgação.

2 Essa classificação se baseia em L ourenço (2000), que em di ssertação de mestrado di scute as diferenças entre objetos científicos, pedagógi cos e de divulgação. 
Apesar da presença desses dois tipos de textos nos museus estudados, é possível identificar também a existência de textos com especificidades que se diferenciam tanto dos científicos quanto dos de divulgação. Esse aspecto será aprofundado a seguir.

\section{D iscutindo aspectos sobre a produção de textos nos museus de ciências}

No que se refere às características dos textos existentes nos museus de ciências, primeiramente é importante destacar que estes nunca são exatamente iguais aos textos científicos ou aos textos de divulgação e esse fato deve-se principal mente ao suporte onde é apresentado e a forma de interação que o visitante/leitor estabelece com ele. Além disso, é fundamental perceber que, na sua grande maioria, os textos em museus dizem respeito ou estão articulados a objetos, sejam eles reais, réplicas ou artefatos. As características particulares dos textos desses locais se referem, de fato, às especificidades de tempo, espaço e objetos da cultura dos museus, o que determina uma forma peculiar de produção e de relação do público com esses produtos.

Por outro lado, é possível perceber a utilização de elementos nesses textos que se aproximam tanto da estrutura gramatical, da lógica e do léxico do texto científico quanto do texto de divulgação. Como foi visto na discussão sobre os textos afixados em museus, Jacobi (1998) indica que muitas vezes os textos de museus, em nome da neutralidade e da objetividade científica, ganham aspecto hermético, impessoal e ausente de emoção, sendo que estes textos eram bastante comuns nos museus clássicos de Arte e de $\mathrm{H}$ istória $\mathrm{N}$ atural. Este tipo de texto encontra-se presente nas exposições e foi observado nos museus estudados na pesquisa.

Vale a pena destacar que é comum a presença de textos com características de textos científicos quando estão relacionados a um objeto científico ou natural, como animais conservados e fósseis ou instrumentos científicos. N os museus onde existem muitos objetos desta natureza e onde a exposição é centrada na transmissão da informação científica, os textos aparecem geralmente se referindo a eles e não são dadas informações para além dos objetos expostos.

No que se refere aos textos semelhantes àqueles de divulgação, esses surgem nas exposições estudadas, geral mente, quando éassumida, na concepção, a orientação voltada para o público. N esses casos é comum notar a presença de conhecimentos dos campos da comunicação e da educação na elaboração dos textos expositivos, que incorporam características dos textos de divulgação, se afastando assim das características do texto científico.

É possível também perceber que não existe somente um tipo de texto em cada exposição, sendo possível encontrar as diferentes características dos textos científicos e dos textos de divulgação nas mesmas exposições e, às vezes, nas mesmas etiquetas expositivas. G eralmente, quando são fornecidas informações sobre o comportamento dos seres vivos, notase a tentativa de se introduzir uma linguagem mais coloquial, passando a incluir elementos didatizantes, como uso de definições, nomeações, metáforas, entre outros. Percebe-se, contudo, que em geral, quanto menos os objetos científicos e naturais (conservados e fósseis) aparecem nas exposições - e quanto mais os objetos de divulgação (artefatos, aparatos multimídias, interativos, etc.) são utilizados, outros tipos de informações são oferecidos através dos textos, para além daquelas de referência direta a esses objetos.

0 maior destaque, no entanto, deve ser dado à caracterização de um texto específico de museu - um texto expositivo. Considera-se um texto especialmente expositivo aquele que na sua estrutura, formato, edição e linguagem leva em consideração as particularidades do espaço de museu e a forma com que o público age neste local, diferenciando-se assim de um texto escrito numa revista ou livro. Esses textos em geral estão associados a objetos e possuem formato que considera a sua leitura no suporte em que está apresentado, tendo cuidado com tamanho de letra, distâncias entre letras e palavras, entre linhas, com a qualidade visual, cor, 
iluminação, preservação, pensando assim naquele eitor que visita o espaço de museu eque em geral realiza uma forma específica de interação.

Além disso, na produção do texto de museu, quando esta leva em conta o público, é tomado cuidado especial quanto ao léxico utilizado. Se direcionado a especialistas, não é aconse Ihável a didatização extrema, já que isso pode inclusive afastar esse tipo de visitante do museu. No entanto, se o alvo é um público mais amplo e se os objetivos são de divulgação e ensino das ciências, a substituição do léxico científico e o uso de recursos metalingüísticos se fazem necessários e são mais comuns para que o texto seja acessível a este tipo de visitante. Foi interessante perceber assim que nem sempre são utilizados elementos didatizantes nos textos dos museus, pois quando há a intenção de atender tanto o público escolar quanto o público especialista, a utilização de estruturas sintáticas de mediação não são tão comuns. Este fato também foi apontado por Jacobi (1998) ao discutir as diferenças entre os textos de vulgarização e os textos afixados em museus.

O s textos específicos de museus possuem assim características próprias. U ma delas diz respeito ao uso de estratégias que conduzem e induzem a uma forma especial de visita pela exposição. N esses casos existem indicações de percursos, de observação de determinados obje tos, de manipulação de outros, de realização de determinadas ações que, em síntese, tem por referência a organização e os elementos presentes no espaço expositivo.

0 utra situação que exemplifica a presença de um tipo de texto de museu é quando, na el aboração de painéis ou hipertextos, as condições de visita são consideradas. N esses casos, elementos referentes ao formato e edição do texto, mas também às cores, formas e imagens são levados em conta na elaboração dos mesmos. A linguagem e estrutura do texto também podem ser consideradas particulares de museus quando estas levam em conta o fato do leitor estar, muitas vezes, em pé e não ter o costume de ler textos longos durante a visita. Assim, as orações são curtas, a mensagem é direta e articula uma próxima ação na exposição.

Em alguns casos especiais os textos assumem características muito específicas, direcionadas a um tipo de público como, por exemplo, o infantil. Em uma das exposições de M 4, por exemplo, houve a incorporação de um personagem à narrativa da exposição procurando a proximidade com o cotidiano e com o público-alvo, através da adequação da linguagem.

O utros aspectos também podem ser evidenciados na análise dos textos presentes nas exposições. Percebese a existência de textos com características semelhantes aos de outras mídias ou suportes, ou mesmo advindos de outros espaços de educação, como aqueles semeIhantes aos dos livros didáticos. Este fato chama atenção para a presença do discurso da escola - com seus saberes e produtos - nos espaços de museus.

Jacobi (1998) levanta, em seu trabalho, questões sobre a possibilidade do processo de introdução de novas tecnologias, como vídeos e hipertextos nas exposições levar ao desaparecimento de textos nos museus. $\mathrm{N}$ a pesquisa realizada se percebeu o contrário: as exposições que possuem esses tipos de objetos de divulgação são, em geral, as que mais possuem textos. Além disso, foi possível também perceber que o fato de se utilizarem novas tecnologias, como hipertexto, não significa necessariamente uma nova abordagem de estrutura e de conteúdos dos textos, já que estes podem se apresentar da mesma forma que, por exemplo, as etiquetas clássicas dos museus onde as características do texto científico predominam.

\section{e desafios}

\section{Considerações finais sobre a produção de textos nos museus: possibilidades}

A partir da análise dos textos existentes em exposições científicas, al gumas observações podem ser feitas. Em geral diferentes públicos freqüentam os espaços de museus, tanto no que se refere ao gênero e à faixa etária, mas também a grupos sociais, origem profissional, etc. Este dado 
torna difícil estabelecer um "leitor padrão" para o qual o texto do museu será direcionado ao ser produzido nestes espaços ${ }^{3}$.

Algumas alternativas para o enfrentamento deste fato seriam, por um lado, escolher 0 público-alvo da exposição - e várias delas fazem exatamente isso, especialmente as exposições dedicadas ao público infantil - para que se garanta a compreensão dos textos por aquela fai xa de visitante selecionada. Por outro, 0 uso de uma diversidade de tipos de textos e de linguagem éum possível caminho se o desejo é atingir a variedade de público que em geral freqüenta estes locais. Assim éfundamental estabelecer objetivos referentes ao público-alvo ao se elaborar exposições em museus de ciências.

Q uanto aos aspectos de formato, estrutura e edição dos textos nos museus, é necessário considerar, na elaboração das exposições, as dimensões referentes ao tempo em que o visitante despende para ler, ao espaço dedicado aos textos, logo também ao suporte - painel, hipertextos ou outros - e aos objetos, os quais são particulares nesses locais e podem variar de natureza, implicando em diferentes formas de interação. A maneira pela qual o público se comporta nas exposições, no quese refere a estas três dimensões, determinam uma maneira especial de apropriação da informação que deve ser levada em conta no processo de produção dos textos nos museus.

Estas considerações valem também para uma reflexão sobre a função e sobre os momentos de introdução dos textos nos museus, já que nem sempre a razão de se colocarem textos nesses espaços é clara para seus idealizadores. M useus não são livros em pé como se costuma ouvir dizer, apesar de muitas exposições serem exatamenteisso. Entender as especificidades da cultura museal e do público que visita esses locais é imprescindível para escolhas conscientes de formato, estrutura, edição, conteúdo e linguagem dos textos nos museus. D aí a necessidade de pesquisas de público que avaliem as inovações tecnológicas e as características dos textos para que estes realmente auxiliem e promovam a leitura nesses locais.

Entretanto as escolhas relativas aos textos nos museus, assim como as demais escolhas sobre a elaboração das exposições, não podem estar descoladas da proposta conceitual que as fundamentam. Tais propostas são reflexos das concepções científicas, museológicas, comunicacionais e educacionais que se encontram na base da produção desta mídia de espaço. Além disso, esta proposta deve estar associada a um marco referencial político-institucional, o qual estabelece as dire trizes para as escol has real izadas no processo de concepção das exposições. Essas concepções e marcos referenciais determinam, enfim, a produção do discurso expositivo.

\section{Referências bibliográficas}

ALLARD, M .; LAROU CHE, M. C.; LEFEBVRE, B.; M EUN IER, A.; VADEBON COEUR, G. La visite au musée. Réseau, p.14-19, D écembre 1995/ Janvier 1996.

BERN ST EIN , B. A Estruturação do D iscurso Pedagógico - classe, códigos e controle Petrópolis: Editora Vozes, 1996.

CAZELLI et al. Tendências Pedagógicas das Exposições de um M useu de Ciência. In: Encontro N acional de Pesquisa em Educação em Ciências, Atas ... Valinhos, São Paulo, setembro 1999.

${ }^{3}$ Wagensberg (2000), por exemplo defende que as exposições não devem ser pensadas visando um público em especial, mas sim devem ser elaboradas para qualquer tipo de visitante. Entretanto é comum a existência de exposições em museus voltadas para determinados públicos, principalmente o infantil, como no La Villette (França), no M useo de La Ciencia (Espanha), entre outros. Por outro lado, é grande a discussão sobre a eficácia de textos direcionados ao público infantil, tanto em exposi ções de museus como em outros mei os de di vulgação científica e este foi tema de debate em mesa-redonda do Encontro de Pesquisa em Educação, Comunicação e D ivulgação em M useus - EPECO DIM, promovido pelo M useu da Vida - FIOCRU Z e M useu de Astronomia e Ciências Afins - M AST, em setembro de 2001. 
COXALL, H. 1994. M useum text as mediated message. In: The Educational role of The M useum. p. 215- 222. Routledge, London.

DEAN, D. M useum Exhibition - Theory and Practice. London Routledge, 1994.

EKARV, M. Combating redundancy: writing texts for exhibition. In H O O PER-GREEN H ILL, E. In: The Educational role of The M useum. p. 201-204. Routledge, London, 1994.

GILM ORE, E. eSABINE, J. Writing readable text: evaluation of the Ekarv M ethod. In: The Educational role of The M useum. p. 205-210. Routledge, London, 1994.

GOUVEAA. G. 2000. A D ivulgação Científica para Crianças. 0 caso da Ciência H oje das Crianças. Tese (D outorado), CCS, UFRJ.

HERN ÁN DEZ, F. H . M anual de M useología. M adrid: Editorial Síntesis, setembro, 1998.

JACO BI, D. Communiquer par L'Écrit dans les M usées. In SCHIELE, B. E KOSTER, E. H. La Révolution de La M uséologie des Sciences. Éditions M ultimondes, Press Universiteires de Lyon, 1998.

LEIBRUDER, A. P. O Discurso de Divulgação Científica. In BRAN D ÃO , H . N . Gêneros de Discurso na Escola. São Paulo: Editora Cortez, 1999.

LO UREN ÇO, M . M useus de Ciência eT écnica: que objectos? Dissertação (M estrado em M useologia e Patrimônio), D epartamento de Antropologia. Faculdade de Ciências Sociais e H umanas. U niversidade N ova de Lisboa, Lisboa, 2000.

M ARAN DIN O, M . 0 Conhecimento Biológico em Exposições de M useus de Ciências análise do processo de produção do discurso expositivo. Tese (D outorado em Educação). Faculdade de Educação, Universidade de São Paulo, 2001.

M ASSARANI, L. A. Divulgação Científica no Rio de Janeiro: Algumas Reflexões sobre a D écada de 20. Dissertação (M estrado). IBICT e Escola de Comunicação, U niversidade Federal do Rio de Janeiro, Rio de Janeiro, 1998.

M O RTIM ER, E. e M ACH AD O , A. M últiplos olhares sobre um episódio de ensino: por que o gelo flutua na água. In: Encontro sobreTeoria e Pesquisa em Ensino de Ciências, Anais.. Faculdade de Educação, Universidade Federal de M inas Gerais, Belo H orizonte, 1997.

VAN -PRAET, M . e POU CET, B. Les M usées, Lieux de Contre-Éducation et de Partenariat Avec L'École, In: Education \& Pédagogies- dés élèves au musée, n. 16, Centre International D'Études Pédagogiques, 1992.

WAGEN SBERG , J. Principios Fundamentales de la M useologia Científica M oderna. Alambique - Didáctica de Las Ciencias Experimentales. n. 26, p. 15 - 19, out/nov, 2000.

\section{Artigo recebido em outubro de 2001 e selecionado para publicação em outubro de 2002.}

